\title{
Impact of Five Days Spiritual Practice in Himalayan Ashram of Sahaj Marg on Well-Being Related Parameters and Selected
} Physiological Indicators

\author{
Narendra Kumar Arya ${ }^{1}$, Kamlesh Singh ${ }^{1}$, Anushree Malik ${ }^{1}$
}

\section{ABSTRACT}

Impact of five days spiritual practice in Himalayan Ashram of Sahaj Marg on well-being related parameters and selected physiological indicators has been studied on 55 participants ( 25 male, 30 female; age range 18-65 years; mean age $=49$ years $\& \mathrm{SD}=12.5$ years). It was found that mental health and its dimensions like emotional well- being and social well-being; positive experience and negative experience; Sat-Chit-Ananda; depression anxiety and stress had significant change towards improved well-being. However, psychological well-being, flourishing Scale and mindfulness did not show significant improvement after the sessions. Observations during the Semi-structured interview corroborated with the above results.

Keywords: Heartfulness, Sahaj Marg, Spiritual Practice, Well-being, Meditation.

All communities have been making efforts to enhance the well-being and happiness of their people. These efforts are mainly of two types: deliberately delivered modules and socio-cultural practices of societies (Singh, Jain \& Singh, 2014). Various studies have been carried out on deliberately induced modules and their efficacy has been well documented (Singh \& Choubisa, 2009; Crawford \& Caltabiano, 2011; Diener \& Diener, 1995; Seligman, Steen, Park \& Peterson, 2005). However socio-cultural practices are also very important as they are practiced widely in all societies with spirituality being central to many cultures.

Spirituality is an integral part of one's identity and the personal experience of the transcendent which may be called God or a higher power, or unity with greater world or mystery, (Gall, Malette \& Guirguis, 2011). Various activities come under the category of spiritual practices with meditation being the core component in most of the eastern spiritual practices. Meditation

\footnotetext{
${ }^{1}$ National Resource Centre for Value Education in Engineering (NRCVEE), Indian Institute of Technology Delhi, New Delhi, India *Responding Author Received: January 11, 2017; Revision Received: February 2, 2017; Accepted: February 7, 2017 (C) 2017 Arya N, Singh K, Malik A; licensee IJIP. This is an Open Access Research distributed under the terms of the Creative Commons Attribution License (www.creativecommons.org/licenses/by/2.0), which permits unrestricted use, distribution, and reproduction in any Medium, provided the original work is properly cited.
} 


\section{Impact of Five Days Spiritual Practice in Himalayan Ashram of Sahaj Marg on Well-Being Related Parameters and Selected Physiological Indicators}

practices can be divided into two categories: focused attention meditation, which requires sustained attention voluntarily on a chosen object, and open monitoring meditation, in which moment to moment content of experience is monitored without reaction (Lutz, Slagter, Dunne, \& Davidson, 2008). Automatic self-transcending meditation practice is a third category of meditation practice which includes techniques designed to transcend their own activity. The category of automatic self-transcending is found to be different from focused attention and open monitoring (Travis \& Shear, 2010).

Individuals with higher level of spiritual well-being have been reported to experience lesser levels of emotional and mental illness (Brown, Carney, Parrish \& Klem, 2013). A new spiritual understanding called three principles, considers mindfulness, flow and mental health as the most natural state of people. This state can be realized and sustained via three spiritual principles which are Universal Mind, Thought and Consciousness. By understanding the three spiritual principles, one can gain insight into "thought recognition" and "innate health via clear mind". This insight has shown significant positive relationship with mindful acceptance, mindful attention, flow experience, and mental health (Kelly, Pransky, \& Lambert, 2016). Universal Mind has been considered as the purest life force; the formless energy and creative intelligence within and behind all of life; the essence of everything in the universe, including human beings, (Banks, 1998).

There are many activities in rural India which have spiritual effects, for example Satsang, which comprises of different prayers and chanting in a group. Satsang has been found to be promoting well-being among women in rural India. Satsang has a spiritual essence that helps a person in connecting with inner self and higher self, also referred to as God (Singh, et al., 2014).

For higher level of spiritual experiences a concept of Sat-Chit-Ananda (Sat meaning being truthful, Chit referring to being aware, and Ananda being the bliss) has been described in Indian spiritual texts. The Indian concept is about achieving bliss or infinite happiness by having the experience of connecting with inner source (Srivastava \& Misra, 2011). A study proposed a scale to measure Sat-Chit-Ananda with adequate psychometric properties in which a multidimensional construct with four dimensions namely Chit-consciousness, Antah Shakti- Inner strength, Sattruthfulness and Ananda- blissfulness was proposed (Singh, Khari, Amonkar, Arya, \& Kesav, 2013).

Meditation is a core component of most of the eastern spiritual practices. Mental and physical health has been found to improve as a result of meditation (Kabat-Zinn, 1994). Empirical studies have confirmed that meditation can indeed foster beneficial psychological and physiological state (Davidson, Kabat-Zinn, Schumacher, Rosenkranz, et al., 2003). Effect of a Buddhist practice Soka Gokai (Soka Gokai International) on well-being and some factors of positive 


\section{Impact of Five Days Spiritual Practice in Himalayan Ashram of Sahaj Marg on Well-Being Related Parameters and Selected Physiological Indicators}

psychology have been studied in a transnational comparison. The practice has been found to be very effective across the nations (Sachar, 2013). In a review of many studies on effect of meditation, it has been found that meditation improves state of mental and physical well-being, (Arya, Singh \& Malik, 2013).

Many Indian organizations with large international following such as Art of Living, Brahma Kumaris, Vipassana and Sahaj Marg are having very effective and popular meditation based programs. These organizations have similar aim of giving spiritual progress, mental peace and happiness through meditation based spiritual practices; however their practices are different in terms of type of meditation, other side-activities and delivery of the programs.

Art of Living runs "Happiness Program" and other programs involving meditation, pranayama (breathing exercises) and sudarshan kriya (a process for cleansing of mind). In a one month study on Sudarshan Kriya Yog (SKY), significant reductions occurred in the pre and post intervention mean Hamilton Anxiety Scale's (HAM-A) total score and psychic subscale (Katzman, Vermani, Gerbarg, Brown, Iorio, et al., 2012). In a review paper on Sudarshan Kriya Yog (SKY), several papers on SKY were studied in which mounting evidence was found to suggest that SKY can be beneficial, low-risk, low-cost adjunct to the treatment of stress, anxiety, post-traumatic stress disorder, depression, stress-related medical illnesses, substance abuse and rehabilitation of criminal offenders (Zope \& Zope, 2013).

Brahma Kumaris practice a technique of Rajyoga (Yoga of mind). Their main focus is on spiritual practices, meditation and self-transformation. It was observed in a study that use of some autonomic and respiratory variables (e.g., heart rate) may reveal group effects of meditation, whereas other variables can alter in an individualistic way (Telles \& Desiraju, 1993). Another ancient Indian technique of meditation is called Vipassana, which means to see things as they really are. In a study on impact of intensive Vipassana meditation, it was found that there was a significant improvement on selected measures of psychological health and well-being, including positive effect, satisfaction with life, and mindfulness whereas there was significant decrease in depression, stress and negative affect measures related to ill-being. However, anxiety subscale of the Depression, Anxiety and Stress Scale (DASS) did not change (Krygier et al., 2013). In another research which reflects author's embodied experience of meditation; Vipassana Meditation is a medium for embodied self-reflexivity. It adds value to the body of knowledge of meditation. Engaging in embodied self-reflexivity has the potential to reduce stress for nurses and other women (Riet, 2011).

Sahaj Marg or Sri Ram Chandra Mission offers a platform for spiritual and practical living in more than 100 countries. Their practice is based on inner experience through meditation. It is a refined and simplified form of Rajyoga, suitable for modern everyday life. Rajyoga refers to 


\section{Impact of Five Days Spiritual Practice in Himalayan Ashram of Sahaj Marg on Well-Being Related Parameters and Selected Physiological Indicators}

meditation and other practices affecting the mind and heart. The Sahaj Marg practice includes a morning meditation, evening cleaning (cleaning of mind) and prayer meditation at bed time. These three basic elements combine to create a complete and effective system for inner transformation. Pranahuti, an ancient yogic technique, also called yogic transmission is the backbone of Sahaj Marg practice. Abhyasi (practitioner) training program at CREST, stay in retreat centers, annual bhandaras (spiritual gatherings), and stay in Himalayan ashram are some of the supporting elements (a full description of courses available at www.sahajmarg.org). There is a lack of empirical studies on Sahaj Marg practices in the published literature. To fill up this gap, the present study has been carried out in which the impact of five days Spiritual Practice in Himalayan Ashram of Sahaj Marg on well-being related parameters and selected physiological indicators have been assessed. At the end of the program, semi-structured interview was conducted to collect responses based on personal experience to correlate the results from quantitative data.

\section{RESEARCH METHODOLOGY}

\section{Participants}

There were fifty five participants ( 25 males, 30 females; age range 18-65 years; mean age $=49$ years $\& \mathrm{SD}=12.5$ years) who participated in the study. The participants were practitioners of Sahaj Marg and were staying full time in the ashram during the five days program. All participants gave informed consent for the purpose of participating in the study.

\section{Study Location}

The study was carried out at the Himalayan Ashram located at Satkhol, District Nainital, Uttarakhand, India. The ashram is located in the foothills of the majestic Himalayas at an elevation of approximately $1900 \mathrm{~m}(5700 \mathrm{ft})$. Satkhol is nestled in a golden valley among orange groves and whispering willows. There is a clear view of majestic Himalayan range in its entire splendor. Organic vegetables and fruits are grown in the ashram for preparing meals for participants.

\section{Daily Routine}

Participants started their day by getting up at 4 a.m. and doing morning meditation and ended their day with prayer meditation. During the day, participants had morning group meditation, evening group meditation, evening thought process cleaning, going to library twice, voluntary work, golden silence, universal prayer and breakfast, lunch and dinner which consisted of simple vegetarian food (Satvic food) prepared using vegetables grown in Ashram compound.

\section{Procedure followed}

Data for the study was collected at the beginning and end of the five day program. The participants arrived on first day of the program and departed in the morning of sixth day. They 


\section{Impact of Five Days Spiritual Practice in Himalayan Ashram of Sahaj Marg on Well-Being Related Parameters and Selected Physiological Indicators}

stayed for the full duration in the Ashram going out only once. Daily schedule comprised of various activities like morning meditation (1 hour), evening meditation (1hour), evening cleaning (15-30 minutes duration mental process using will power, which is part of the spiritual practice), universal prayer (15minutes), prayer meditation before going to bed (10minutes), library time (2-3 hours), golden silence (30 min), voluntary work (1hour) etc.

\section{Psychological tests}

A booklet for data collection was prepared containing demographic information and selected psychological tests. The booklet also contained a consent form which was to be signed by the participants. The booklet was bilingual having each question in English and Hindi both. Bilingual experts translated the original English version to Hindi language for use in the study. The tests were later back-translated into English by bilingual experts to verify the content similarity to the original scales and to ensure that translated tests were true copy of the original tests. The discrepancies were resolved and the data collection booklet was verified once again by the authors and bilingual experts. The psychological tests used are given below:

1. Mental Health Continuum- Short Form (MHC - SF; Keyes, 2005): This test consists of 14 items. Three items represent emotional well-being, six items represent psychological wellbeing, and five items represent social well-being with 6 point Likert scale (0-never to 5-every day). The internal reliability reported for total MHC score was $\alpha=0.89$, for emotional wellbeing $\alpha=0.83$, for psychological well-being $\alpha=0.83$ and for social well-being $\alpha=0.74$ (Lamers, Westerhof, Bohlmeijer, Klooster \& Keys, 2011). In a study on Indian population, accepted alpha reliability for Emotional Well-Being $(\alpha=0.82)$, Social Well-Being $(\alpha=0.79)$ and Psychological Well-Being $(\alpha=0.83)$ have been reported, (Singh, 2014).

2. Scale of Positive and Negative Experience (SPANE, Diener et al., 2010): This is a 12 item scale which is rated on 5 point Likert scale. The measure of feelings like good, pleasant, happy, joyful, contented, bad, unpleasant, sad, afraid and angry are rated on a scale of 1-5 (from Very Rarely or Never (1) to Very Often or Always (5)). The scale reveals positive feelings score (SPANE-P, $(\alpha=0.87$ ), negative feelings score (SPANE-N, $\alpha=0.81$ ) and SPANE-B (The two scores can be combined by subtracting the negative score from the positive score, and the resulting SPANE-B scores can range from -24 to 24). Cronbach's coefficient for SPANE-P $(\alpha=0.81$ and for SPANE-N $(\alpha=0.77)$ were also acceptable in Indian study (Singh, 2014).

3. Flourishing Scale (FS; Diener et al., 2010): This is a 7 point Likert scale with 8 statements to assess flourishing. The possible range of scores is from 8 (lowest possible) to 56 (highest possible). A high score represents a person with many psychological resources and strengths. Diener et al., (2010) reported very good Cronbach's alpha $(\alpha=0.87)$. Confirmatory Factor Analysis (CFA) results were acceptable and Cronbach coefficient was found to be excellent $(\alpha=0.93)$ on Indian population (Singh, 2014). 
Impact of Five Days Spiritual Practice in Himalayan Ashram of Sahaj Marg on Well-Being Related Parameters and Selected Physiological Indicators

4. Sat-Chit-Ananda scale (Sat-Chit-Ananda; Singh et.al, 2013): The scale has seventeen items, having four factors with acceptable psychometric properties, namely, ChitConsciousness $(\alpha=0.76)$, Antah Shakti - Inner Strength $(\alpha=0.76)$, Sat- Truthfulness $(\alpha=0.69)$ $\&$ Ananda - Blissfulness $(\alpha=0.64)$ and overall Sat-Chit-Ananda scale $(\alpha=0.82)$.

5. Mindful Attention Awareness Scale (MAAS; Brown and Ryan, 2003): This is a 15-items scale designed to assess a core characteristic of mindfulness. Internal consistency is good with alpha ranging from 0.80 to 0.90 (Brown \& Ryan, 2003).

6. Depression, Anxiety and Stress Scale (DASS 21; Lovibond \& Lovibond, 1995): The DASS 21 is a set of three self-report scales designed to measure the negative emotional states of depression, anxiety and stress. Each of the three DASS 21 scales contains 7 items. Scores for Depression, Anxiety and Stress are calculated by summing up the scores for the relevant items. Internal consistency is good with $\alpha=0.96,0.89$ and 0.93 for Depression, Anxiety and Stress, respectively (Brown et al., 1997).

\section{Physiological and physical health parameters for study}

Blood pressure and heart rate were measured at beginning and end of the program as physiological parameters. Measurement of blood pressure and heart rate was carried out using commercially available automatic blood pressure monitor of brand-Omron model SEM-1(HEM7051-C12). Each participant was asked to take rest for 5 minutes and then the measurement was taken.

\section{Semi structured interview}

Semi-structured interview was conducted with help of questionnaire comprising of seven questions. Participants were asked many questions e.g. why have you come for this program, how long have you been doing Sahaj Marg practice, how regular you are in your practice, how much improvement you feel in your spiritual condition during this program, which activities you liked most in this program, which activities you did not like in this program and anything you want to say on your own.

\section{Data analysis}

Data was analyzed using SPSS version 16. Paired t-test was used to study the effect of spiritual practice based program as it was a pre-post study.

\section{RESULTS}

\section{Well-being related parameters}

There was a significant difference in the scores for the MHC-SF (Total) in pre $(\mathrm{M}=52.42, \mathrm{SD}=$ $10.57)$ and post sessions $(\mathrm{M}=57.12, \mathrm{SD}=9.39) ; t(49)=3.06, \mathrm{p}<0.01$. At component level also, there was a significant difference for emotional well-being scores $\{(\operatorname{Pre} \mathrm{M}=11.72, \mathrm{SD}=$ 2.86 and post sessions $\mathrm{M}=13.04, \mathrm{SD}=2.38), t(49)=2.69, \mathrm{p}<0.01)\}$ and for social well-being 


\section{Impact of Five Days Spiritual Practice in Himalayan Ashram of Sahaj Marg on Well-Being Related Parameters and Selected Physiological Indicators}

scores $\{($ pre $\mathrm{M}=16.68, \mathrm{SD}=5.70$ and post sessions $\mathrm{M}=18.88, \mathrm{SD}=4.57), t(49)=3.24, \mathrm{p}<$ $0.01\}$.Values of Sat-Chit-Ananda scale also improved significantly $\{($ pre $\mathrm{M}=73.43, \mathrm{SD}=9.48$ ) and post-sessions $\mathrm{M}=76.02, \mathrm{SD}=6.89) ; t(50)=2.22, \mathrm{p}<0.05\}$.

Table 1: Paired t- test of Pre and Post sessions data for well-being related parameters

\begin{tabular}{|l|l|l|l|l|l|l|}
\hline \multirow{2}{*}{ Factor } & \multicolumn{2}{|c|}{ Pre - Testing } & \multicolumn{2}{l|}{ Post -Testing } & N & t - values \\
& Mean & SD & Mean & SD & & \\
\hline MHC-SF (Emotional) & 11.72 & 2.86 & 13.04 & 2.38 & 50 & $-2.69^{* *}$ \\
\hline MHC-SF (Social) & 16.68 & 5.70 & 18.88 & 4.57 & 50 & $-3.24^{* *}$ \\
\hline MHC-SF (Psychological) & 24.02 & 4.86 & 25.20 & 4.34 & 50 & -1.61 \\
\hline MHC-SF (Total) & 52.42 & 10.57 & 57.12 & 9.39 & 50 & $-3.06^{* *}$ \\
\hline SPANE-Positive & 23.57 & 3.88 & 26.22 & 3.57 & 49 & $-5.03^{* *}$ \\
\hline SPANE-Negative & 13.33 & 3.33 & 10.92 & 3.51 & 49 & $5.16^{* *}$ \\
\hline SPANE-Balance & 10.24 & 5.84 & 15.31 & 6.57 & 49 & $-6.40^{* *}$ \\
\hline Flourishing Scale & 47.18 & 8.18 & 49.69 & 8.23 & 55 & -1.94 \\
\hline Sat-Chit-Ananda & 73.43 & 9.48 & 76.02 & 6.89 & 51 & $-2.22^{*}$ \\
\hline MAAS & 66.74 & 15.72 & 71.20 & 15.54 & 50 & -1.52 \\
\hline DASS(Depression) & 4.57 & 4.81 & 3.27 & 4.26 & 49 & $2.75^{* *}$ \\
\hline DASS(Anxiety) & 4.76 & 4.47 & 3.61 & 4.08 & 49 & $2.24^{*}$ \\
\hline DASS (Stress) & 5.82 & 4.40 & 4.00 & 4.38 & 49 & $3.01^{* *}$ \\
\hline DASS (Total) & 15.14 & 12.51 & 10.88 & 11.73 & 49 & $3.14^{* *}$ \\
\hline
\end{tabular}

Note: $M H C-S F=$ Mental Health Continuum Short Form, SPANE= Scale of Positive and Negative Experiences, MAAS= Mindful Attention Awareness Scale, DASS= Depression, Anxiety and Stress Scale. * Significant $p<0.05 \quad * *$ significant $p<0.01$

In SPANE, Scores on positive feelings $\{$ (pre $\mathrm{M}=23.57, \mathrm{SD}=3.88$ and post sessions $\mathrm{M}=26.22$, $\mathrm{SD}=3.57) ; t(48)=5.03, \mathrm{p}<0.01)$ and Balance scores $\{($ pre $(\mathrm{M}=10.24, \mathrm{SD}=5.84$ and post sessions $(\mathrm{M}=15.31, \mathrm{SD}=6.57) ; t(48)=6.40, \mathrm{p}<0.01\}$ were increased significantly whereas negative feelings $\{($ pre $\mathrm{M}=13.33, \mathrm{SD}=3.33$ and post sessions $\mathrm{M}=10.92, \mathrm{SD}=3.51) ; t(48)=$ 5.16, $\mathrm{p}<0.01)\}$, Depression $\{($ pre $\mathrm{M}=4.57, \mathrm{SD}=4.81$ and post sessions $(\mathrm{M}=3.27, \mathrm{SD}=4.26)$; $\mathrm{t}(48)=2.75, \mathrm{p}<0.01)\}$, Anxiety $\{($ pre $(\mathrm{M}=4.76, \mathrm{SD}=4.47$ and post sessions $(\mathrm{M}=3.61, \mathrm{SD}=$ $4.08) ; \mathrm{t}(48)=2.24, \mathrm{p}<0.05)\}$ and Stress $\{($ pre $(\mathrm{M}=5.82, \mathrm{SD}=4.40)$ and post sessions $(\mathrm{M}=$ $4.00, \mathrm{SD}=4.38) ; t(48)=3.01, \mathrm{p}<0.01)\}$ were decreased significantly. However, there was no significant changes in flourishing, psychological well-being and mindfulness in this study (see Table 1).

\section{Physiological parameters}

Physiological measures (Blood Pressure and Heart Rate) were taken as dependent variables in the study to observe any change in them. Blood Pressure (diastolic) $\{$ (pre $(\mathrm{M}=85.31, \mathrm{SD}=$ 
11.79) and post sessions $(\mathrm{M}=77.21, \mathrm{SD}=10.42) ; t(41)=5.50, \mathrm{p}<0.01)\}$ and heart Rate changed significantly (pre $(\mathrm{M}=77.52, \mathrm{SD}=10.41)$ and post sessions $(\mathrm{M}=86.12, \mathrm{SD}=9.58) ; t$ $(41)=7.92, p<0.01)\}$. However, there was no significant change in blood pressure (systolic) values (see Table no. 2).

Table 2: Analysis of Pre and Post data for physical health related parameters

\begin{tabular}{|l|c|l|l|l|l|l|}
\hline \multirow{2}{*}{ Factor } & \multicolumn{2}{|c|}{ PRE- Testing } & \multicolumn{2}{l|}{ POST-Testing } & \multirow{2}{*}{ N } & \multirow{2}{*}{ t- values } \\
& Mean & SD & Mean & SD & & \\
\hline Blood Pressure (systolic) & 133.55 & 29.95 & 128.90 & 16.53 & 42 & 1.25 \\
\hline Blood Pressure (diastolic) & 85.31 & 11.79 & 77.21 & 10.42 & 42 & $5.50^{* *}$ \\
\hline Heart Rate & 77.52 & 10.41 & 86.12 & 9.58 & 42 & $-7.92^{* *}$ \\
\hline
\end{tabular}

$* *$ Significant $p<0.01$

However, when we critically analyze the blood pressure data as per the American Heart Association Standards, the number of participants in normal range (BP Systolic $<120$ and BP Diastolic < 80) increased from 7 to 12 (Fig 1). Participants in Pre-hypertension stage (BP Systolic 120-139 or BP diastolic 80 - 89) increased from 15 to 19. Participants in High blood Pressure Stage 1 (BP Systolic 140-159 or BP diastolic 90 - 99) decreased from 11 to 9. Participants in High Blood Pressure Stage 2 (BP Systolic > 160 or BP diastolic > 100) decreased from 4 to 2. Very important thing to note is that participants in hypertensive crisis condition reduced from 5 to 0 (Fig. 1 ).

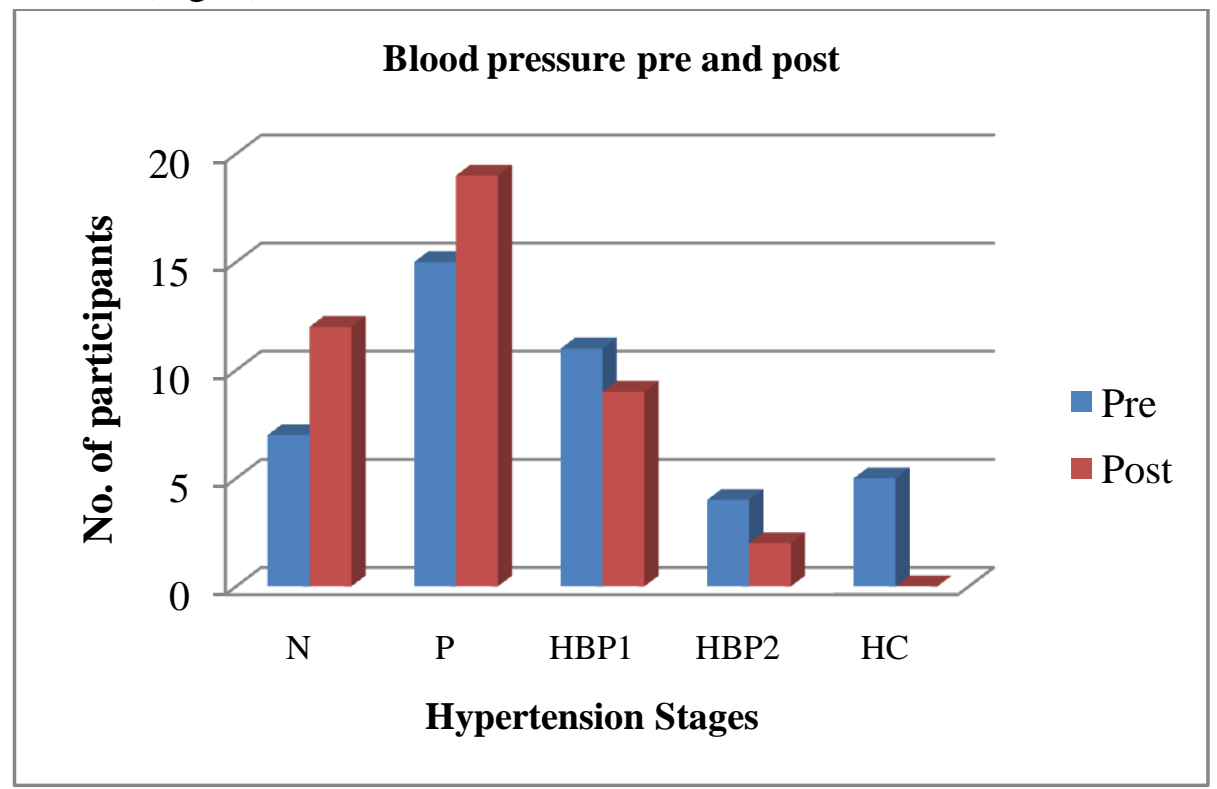

Figure 1: Number of participants in various stages of hypertension

N-Normal; P-Pre-hypertension; HBP1-High Blood Pressure Stage 1;

HBP2-High Blood Pressure Stage 2; HC-Hypertensive Crisis 


\section{Impact of Five Days Spiritual Practice in Himalayan Ashram of Sahaj Marg on Well-Being Related Parameters and Selected Physiological Indicators}

\section{Semi Structured Interview}

To assess the impact of the program in qualitative terms, semi structured interview was conducted. Replies to the questions are given below.

Q1 Why have you come for this program?

Majority of participants replied that they have come for spiritual progress. Many replied that they have come for mental peace, uniqueness of Himalayan Ashram at Satkhol, to participate in the program at Himalayan Ashram, to experience the atmosphere. Some people replied that they wanted to be one with nature and also because the spiritual master likes the place very much. Some wanted to experience the silence of Himalayas.

Q2 How long have you been practicing Sahaj Marg?

Experiences of participants spanned over a very wide range with eight participants having experience up to five years and another five having experience of more than 20 years (Fig. 2). Twenty five participants were in the range of five to ten years whereas sixteen were in the range of ten to twenty years. One participant did not report the experience. When asked to elaborate, some reported that they discontinued for some time, some said that with the grace of master they were active till now. Some reported that they are continuing because of interest in meditation and spirituality and also their faith in the absolute.

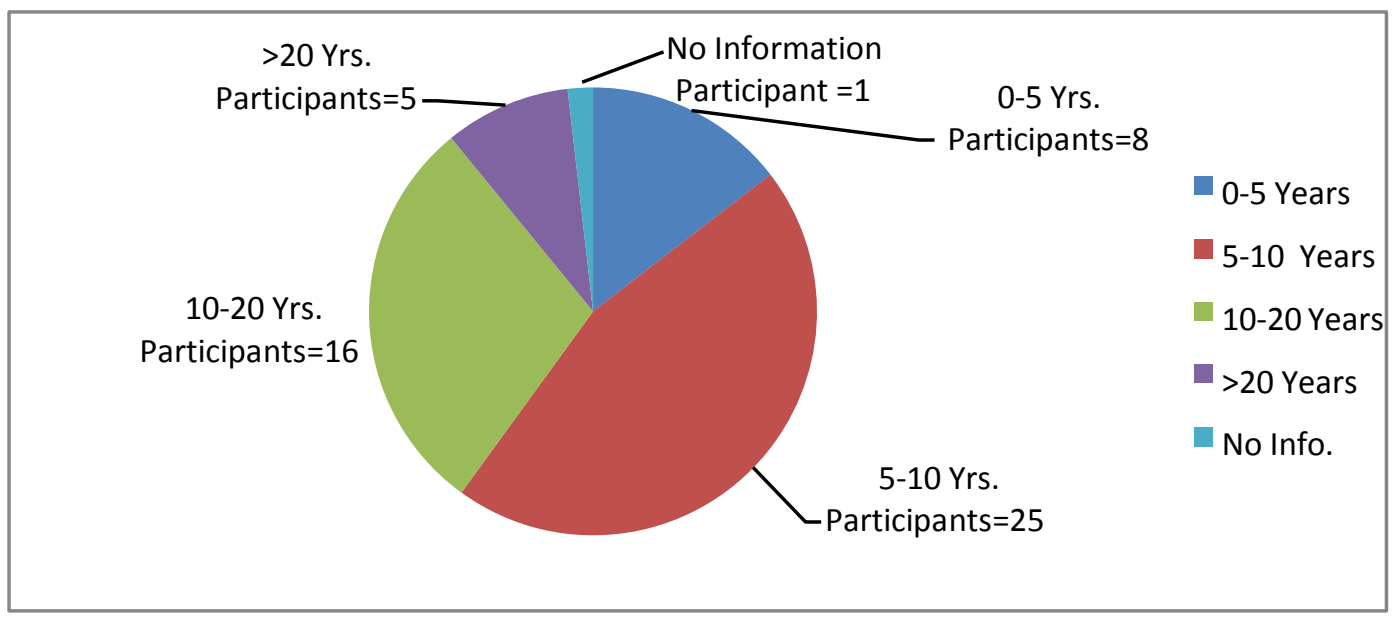

Figure 2. Duration of meditation practice

Q3 How regular you are in your practice? (Rate between 1-seldom to 5-Regular)

When asked about the regularity of meditation practice on a scale of 1-5 (1- seldom to 5regular), thirty two of them reported the highest number 5 (Fig. 3). Twelve of them reported 4 while nine of them reported 3. One participant reported two and nobody reported 1 whereas for one participant data was not available. When asked to elaborate, some reported that they were regular in all aspects of practice whereas some reported that they were regular in the morning meditation but irregular in cleaning. Some reported their irregularity due to laziness whereas 
some others had lack of reason for irregularity. One person reported that he was missing diary writing where as one reported that his practice has improved in Satkhol.

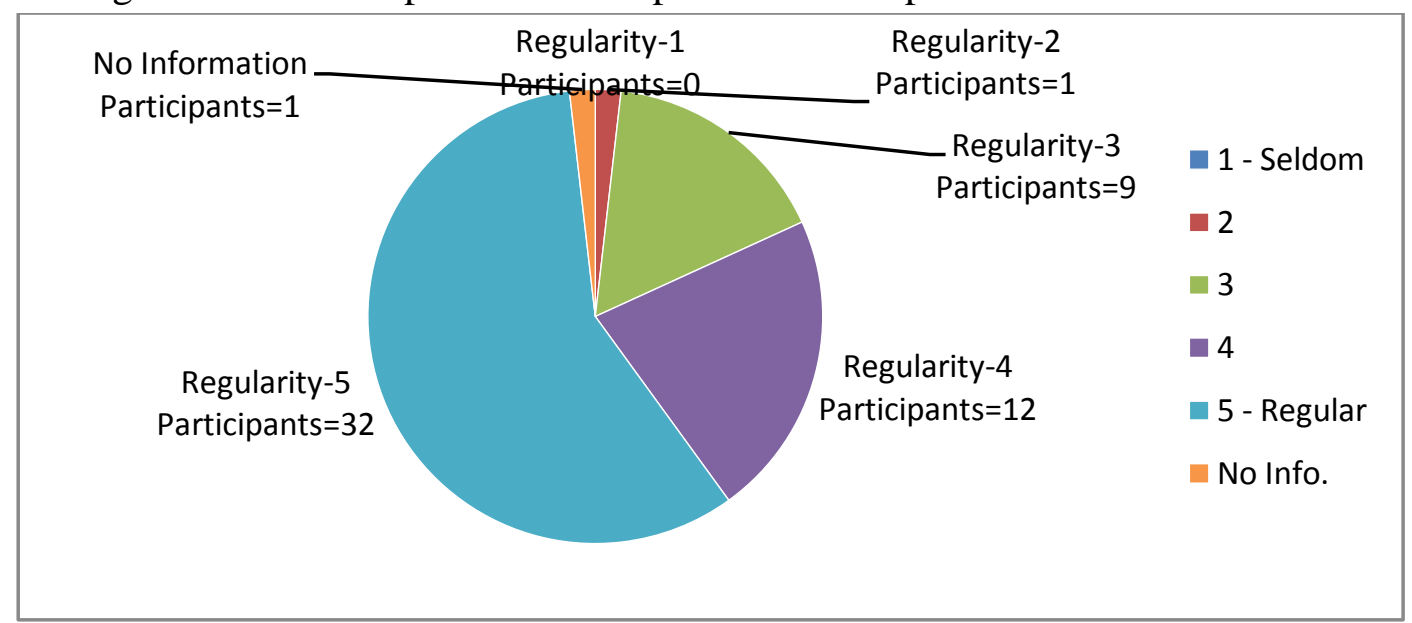

Figure 3: Regularity of meditation practice

Q4 How much improvement you feel in your spiritual condition during this program?

When asked about the improvement in spiritual condition during the program on a scale of 1-5 (1- Negligible, 5- Tremendous), thirty five of them reported the highest number 5 (Fig. 4). Sixteen of them reported 4 while three of them reported 3. None of them reported 1 or 2 whereas for one participant, data was not available. When asked to elaborate, some reported that their mind was totally at peace and they developed art of listening to nature silently, some felt totally absorbed in meditation, for some the regularity of practice and sensitivity has increased. One participant reported that he was fully focused on the program without deviation due to group effect while one reported that exploring self was much easier here.

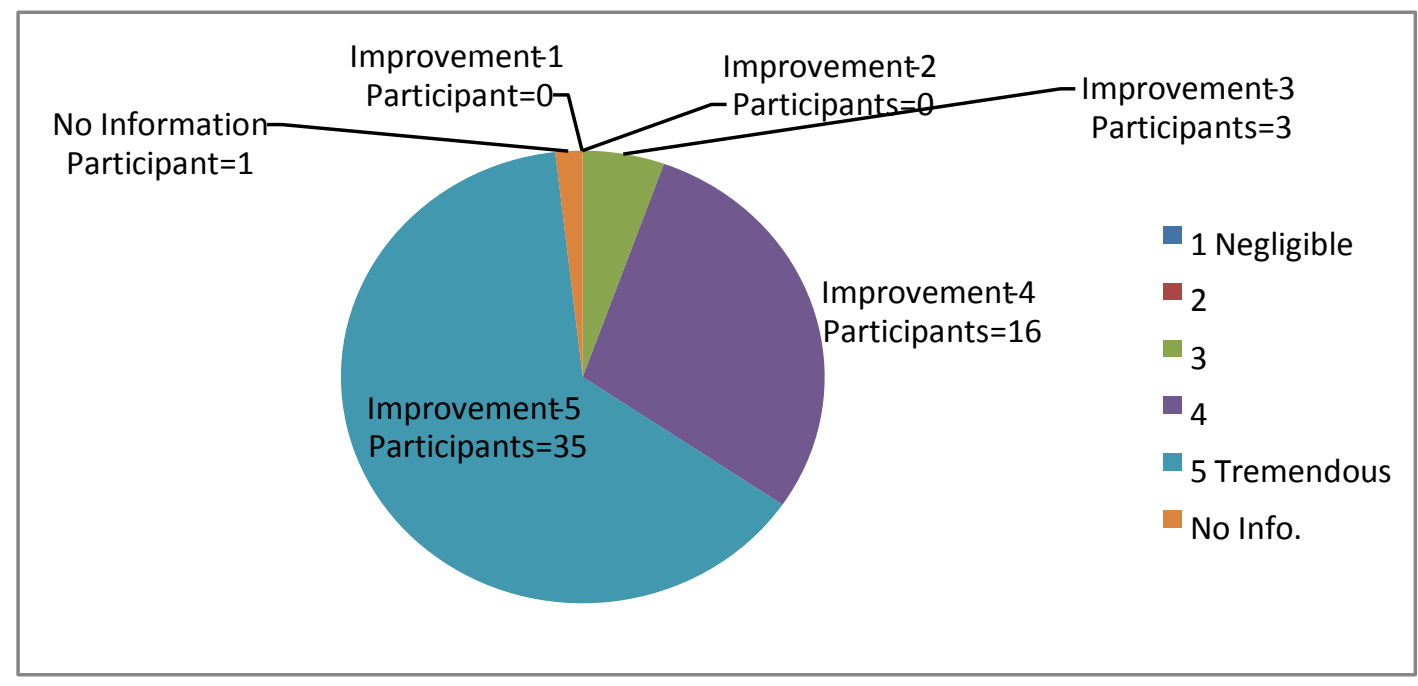

Figure 4. Improvement in spiritual condition during the program 


\section{Impact of Five Days Spiritual Practice in Himalayan Ashram of Sahaj Marg on Well-Being Related Parameters and Selected Physiological Indicators}

\section{Q5. Which activities you liked most in the program?}

Six participants reported that they liked all the activities whereas many reported that they liked meeting the Master. Many participants replied that they liked volunteer work, meditation, cleaning process, peaceful atmosphere, introspection, group meditation etc. Some people liked heart fulness program where as some liked the nature walks.

\section{Q6. Which activities you did not like in the program?}

Eight participants reported that there was no activity which they did not like. One participant did not like filling this format; one did not like being left totally free whereas one did not like not having time for introspection. One person felt that unnecessary fear was created about rules and regulations in the Ashram. All other participants did not answer the question.

\section{Q7 Anything you want to say on your own?}

Many participants felt very good, with two saying that it is like heaven. Some participants wanted to thank the Master for the opportunity. Some felt free inside whereas some felt the real experience of meditation. Some wanted to come again whereas some said that participants are wonderful. One participant wanted to stay there only after retirement whereas one appreciated the program. Another participant felt differently during meditation which was never felt earlier. Twenty seven participants did not mention anything.

\section{DISCUSSION}

Main aim of this work was to study the effect of spiritual practices at Himalayan Ashram of Sahaj Marg on well-being related parameters. There were significant improvements in measures of well-being like positive experiences, Emotional well-being, Social well-being and Sat-ChitAnanda. In a similar study, brief mindfulness mediation training was effective at increasing mindfulness skill, reducing negative mood and fatigue (Zeidan, et. al, 2010). In another study on Satsang carried out in rural India, it was observed that all the rural women participating in Satsang felt more empowered and free from stressors (Singh, et al., 2014). Satsang also has spiritual essence similar to Sahaj Marg Spiritual Practice. In another study it was found that the mindfulness meditation significantly reduces stress levels and it was effective in reducing repetitive and persistent thinking (Kang, Choi \& Ryu, 2009). Considering various studies cited about meditation effects earlier, it can be interpreted that the well-being related parameters have moved on expected lines showing significant improvement. The insignificant result on mindfulness may also be attributed to this kind of practice which is heart centered instead of mind. In this practice, practitioners are encouraged to be heart centered, however, they observe through introspection what is going on in the mind as a secondary thing.

Depression, Anxiety and Stress have reduced significantly in this study. Consistent to these results, Rocha et al, (2012) have found that regular yoga practice reduced stress, depression and 


\section{Impact of Five Days Spiritual Practice in Himalayan Ashram of Sahaj Marg on Well-Being Related Parameters and Selected Physiological Indicators}

anxiety and it also improved performance in a recognition memory task. In the same study, Salivary Cortisol analysis indicated that yoga practice reduces physiological parameter indicative of stress levels. In a similar study based on Pranayama, it was found that regular practice of pranayama had a positive effect in lowering the test anxiety (Nemati, 2013). A study on effect of negative air ions concentration found that there was a decline in computer oriented stress and psychological stress (Malik, Singh, \& Singh, 2010). The pristine environments similar to Himalayan Ashram are known to harbor high density of beneficial negative air ions (Suni, et. al, 2007). This may also be relevant as the decrease in stress may be partly due to higher levels of negative air ions in natural surroundings, where sessions of the study were conducted.

In selected physical health indicators, there was significant improvement in Blood Pressure Diastolic values in spite of the fact that normally blood pressure increases at higher altitudes (Lang, et al., 2016; Stöwhas, et al, 2013). However, mean Heart Rate values have gone slightly up instead of improvement. It is difficult to explain this negative effect, however, one of the possible reasons may be the higher altitude (Stöwhas, et al, 2013). In a related study, a meditation group performed mindfulness meditation 30 minutes daily for seven consecutive days. They were found to have reduction in Systolic blood pressure and anxiety scale scores (Yu, Xueling, Liyuan \& Xiaoyuan, 2013). Another study observed that higher blood pressure (BP) participants in the Mindfulness Based Stress Reduction (MBSR) group had lower BP at week 8 relative to control group (Tavis, et. al, 2012). In a study on 50 healthy subjects (24 males and 26 females), it was found that heart rate, systolic BP and diastolic BP after pranayama and meditation for 15 days, went down (Roopa, et. al, 2011). In another study on borderline hypertensive subjects, it was found that relaxation and meditation technique is an effective method of lowering borderline hypertensive blood pressures (Benson, Rosner, Marzetta, \& Klemchuk, 1974).

In the present study, semi-structured interview was also conducted to study attitude towards the program. It has been found that results obtained for well-being related indicators correlate well with responses of semi-structured interview. Remarkable improvement was reported by most of the participants in their spiritual level. This reflects a support to self-report measures results. The fact that they liked most of the activities in the program also points towards participants feeling contended.

Some participants had higher blood pressure, however it could not be ascertained whether they had similar problem before starting the practice of Sahaj Marg. Moreover what other difficulties they are facing in life has not been asked for. Hence it cannot be explained how the practice worked for them before the program, which is a limitation of this study. Also, to more clearly pin point the main factor (the practice, the location, the Master, or all of them) responsible for benefits, control group is desirable. It would have been better to have a control group such as a 


\section{Impact of Five Days Spiritual Practice in Himalayan Ashram of Sahaj Marg on Well-Being Related Parameters and Selected Physiological Indicators}

group of people who practiced but did not attend the ashram, however it was not feasible due to physical limitations of the research team as the ashram is too far away and participants come from different parts of the world, with different backgrounds. Getting people of similar backgrounds at a place other than ashram and not doing any spiritual practice was very difficult and hence this can be considered a limitation. Follow up measurement could also not be done which adds to limitations in terms of finding whether the effect is lasting or not. Future research can explore impact of spiritual practices, locations (ashrams, nature trip etc.), the Master (spiritual/ religious guru) and other factors on well-being.

\section{CONCLUSION}

The results of the self-report measures suggest that due to the program, mental health and its emotional and social well-being components, positive experience, Sat-Chit-Ananda showed improvement whereas Depression, Anxiety, Stress and their total score had significant reduction. However, Psychological well-being, Flourishing and mindfulness did not have significant change. Results of well-being and ill-being related parameters, physiological parameters and semi-structured interview indicate perceived change towards general improvement.

\section{Suggestions for Future Studies}

Sahaj Marg spiritual practice is finding more and more acceptance throughout the world; however it has not been researched much. It is also being spread by the name Heart fulness as an experience even for those who may not like to follow the regular practice of Sahaj Marg for long duration. It is suggested that effect of heart fulness programs of Sahaj Marg aimed at nonpractitioners could also be studied in different settings. Moreover, the inclusion of control group as well as wider physiological parameters can be considered to strengthen the results in future studies.

\section{Conflict of Interests}

The authors declared no conflict of interests.

\section{REFERENCES}

Arya, N. K., Singh, K., \& Malik A. (2013).Effect of Meditation on work performance, state of mind and health. Jigyasa Visheshank, 1, 48-52.

Banks, S. (1998). The missing link. Vancouver, BC: Lone Pine.

Benson, H., Rosner, B.A., Marzetta, B.R., \& Klemchuk, H.P. (1974). Decreased blood pressure in borderline hypertensive subjects who practiced meditation. Journal of Chronic Diseases, 27 (3), 163-169.

Brown, D.R., Carney, J.S., Parrish, M.S., \& Klem, J.L. (2013). Assessing Spirituality: The Relationship between Spirituality and Mental Health, Journal of Spirituality in Mental Health, 107-122. 


\section{Impact of Five Days Spiritual Practice in Himalayan Ashram of Sahaj Marg on Well-Being Related Parameters and Selected Physiological Indicators}

Brown, K.W. \& Ryan, R.M. (2003). The benefits of being present: Mindfulness and its role in psychological well-being. Journal of Personality and Social Psychology, 84, 822-848.

Brown, T.A., Chorpita, B.F., Korotitsch, W., \& Barlow, D.H. (1997). Psychometric Properties of the Depression Anxiety Stress Scales (DASS) in clinical samples. Behav. Res. Ther., 35 (1), 79-89.

Crawford, S.A. \& Caltabiano, N.J. (2011). Promoting emotional well-being through the use of humour. The Journal of Positive Psychology, 6(3), 237-252.

Davidson, R.J., Kabat-Zinn, J., Schumacher, J., Rosenkranz, M., Muller, D., Santorelli, S.F., Urbanowski, F., Harrington, A., Bonus, K., \& Sheridan, A.F. (2003). Alterations in brain and immune function produced by mindfulness meditation. Psychosomatic Medicine, 65, 564-570.

Diener, E., \& Diener, M. (1995). Cross-cultural correlates of life satisfaction and self-esteem. Journal of Personalities and Social Psychology, 68, 653-663.

Diener, E., Wirtz, D., Tov, W., Kim-Prieto, C., Choi, D. W., Oishi, S., \& Biswas-Diener, R. (2010). New well-being measures: Short scales to assess flourishing and positive and negative feelings. Social Indicator Research, 97, 143-156.

Gall, T.L., Malette, J., \& Guirguis-Younger, M. (2011). Spirituality and Religiousness: A Diversity of Definitions. Journal of Spirituality in Mental Health, 13(3), 158-181.

Kabat-Zinn, J. (1994). Wherever you go, there you are: Mindfulness meditation in everyday life. New York: Hyperion.

Kang, Y.S., Choi, S.Y., \& Ryu, E. (2009). The effectiveness of a stress coping program based on mindfulness meditation on the stress, anxiety, and depression experienced by nursing students in Korea. Nurse Education Today, 29, 538-543.

Katzman, M.A., Vermani, M., Gerbarg, P.L., Brown, R.P., Iorio, C., Davis, M., Cameron, C., \& Tsirgielis, D. (2012). A multicomponent yoga-based, breath intervention program as an adjunctive treatment in patients suffering from generalized anxiety disorder with or without comorbidities. International Journal of Yoga,5, 57-65.

Kelly, T.M, Pransky, J., \& Lambert, E.G. (2016). Realizing Improved Mindfulness/ Flow/Mental Health Through Understanding Three Spiritual Principles. Journal of Spirituality in Mental Health, 1-18.

Keyes, C.L.M. (2005). Mental illness and/or mental health? Investigating axioms of the complete state model of health. Journal of Consulting and Clinical Psychology, 73(3), 539-548.

Krygier, J.R., Heathers, J.A.J., Shahrestani, S., Abbott, M., Gross, J.J., \& Kemp, A.H. (2013). Mindfulness meditation, well-being, and heart rate variability: A preliminary investigation into the impact of intensive Vipassana meditation. International Journal of Psychophysiology, 89, 305-313.

Lamers, S. M., Westerhof, G. J., Bohlmeijer, E. T., Ten Klooster, P. M., \& Keyes, C. L. M. (2011). Evaluating the psychometric properties of the Mental Health Continuum-Short Form (MHC-SF). Journal of Clinical Psychology, 67, 99-110. 


\section{Impact of Five Days Spiritual Practice in Himalayan Ashram of Sahaj Marg on Well-Being Related Parameters and Selected Physiological Indicators}

Lang, M., Faini, A., Caravita, S., Bilo, G., et al. (2016). Blood pressure response to six-minute walk test in hypertensive subjects exposed to high altitude: effects of antihypertensive combination treatment. International Journal of Cardiology, 219, 27-32.

Lovibond, P.F. \& Lovibond, S.H. (1995). The structure of negative emotional states: comparison of the Depression Anxiety Stress Scales (DASS) with the beck depression and anxiety inventories. Behav Res Ther, 33 (3), 335-342.

Lutz, A., Slagter, H. A., Dunne, J.D., \& Davidson,R.J. (2008). Attention regulation and monitoring in meditation. Trends in Cognitive Sciences,12(4),163-169.

Malik, A., Singh, K., \& Singh, M.(2010). Effect of negative air ions on physiological and perceived psychological stress during computer operation. Int. Journal. Environment and Health, 4, 67-77.

Nemati, A. (2013). The effect of pranayama on test anxiety and test performance. International Journal of Yoga, 6, 55-60.

Riet, P.V.D. (2011). Vipassana meditation: One woman's narrative. Collegian, 18, 36-42.

Rocha, K.K.F., Ribeiro, A.M., Rocha, K.C.F., Sousa, M.B.C., Albuquerque, F.S., Ribeiro, S., \& Silva, R.H. (2012). Improvement In physiological and psychological parameters after 6 months of Yoga practice", Consciousness and Cognition, 21, 843-850

Roopa, B. A., Anita, H., Shailaja, P., Shashikala,G.V., \& Surekharani, C. (2011). Effect of shortterm pranayama and meditation on cardiovascular functions in healthy individuals. Heart Views, 12, 58-62.

Sachar, R. (2013). Impact of a Buddhist practice on psychological well-being and related factors of positive psychology: a transnational comparison (Unpublished Doctoral thesis, Indian Institute of Technology, Delhi, India).

Seligman, M.E.P., Steen, T.A., Park, N., \& Peterson, C. (2005). Positive psychology progress: Empirical validation of interventions. American Psychologist, 60, 410-421.

Singh, K. (2014). Relationship of demographic variables, socio-cultural issues and selected psychological constructs with the positive mental health of North Indian adolescents. ICMR Project Report.

Singh, K., \& Choubisa, R. (2009). Effectiveness of self-focused intervention for enhancing students well- being. Journal of Indian Academy of Applied Psychology, 35, 23-32.

Singh, K., Jain. A, \& Singh, D. (2014). Satsang: A culture specific effective practice for wellbeing. Springer Science+Business Media Dordrecht.

Singh, K., Khari, C., Amonkar, R., Arya, N.K., \& Kesav, S.K. (2013). Development and validation of a new scale: sat-chit-ananda scale. International Journal on Vedic Foundations of Management, 1, 54-74.

Srivastava, A.K., \& Misra, G. (2011). New directions in health psychology. In A. K. Dalal \& G. Misra (Eds.) (pp. 109-131). New Delhi: Sage. 


\section{Impact of Five Days Spiritual Practice in Himalayan Ashram of Sahaj Marg on Well-Being Related Parameters and Selected Physiological Indicators}

Stöwhas, A.C., Latshang, T.D., Lo Cascio, C.M., Lautwein, S, Stadelmann, K., et al. (2013). Effects of Acute Exposure to Moderate Altitude on Vascular Function, Metabolism and Systemic Inflammation. PLoS ONE, 8(8): e70081.

Suni, T., Kulmala, M., Hirsikko, A., Bergman, T., Laakso, et al., (2007). Formation andcharacteristics of ions and charged aerosol particles in a native Australian Eucalypt forest. Atmospheric Chemistry and Physics Discussions, European Geosciences Union, 7(4), 10343-10369.

Telles, S., Desiraju, T. (1993). Autonomic changes in Brahmakumaris raja yoga meditation. International Journal of Psychophysiology, 15, 147-152.

Travis, F., \& Shear, J. (2010). Focused attention, open monitoring and automatic selftranscending: Categories to organize meditations from vedic, Buddhist and Chinese traditions. Consciousness and Cognition, 19, 1110-1118.

Travis, S.C., Laura, E.L., Simon, L.B., Peter, F., \& Linda, E.C. (2012). Impact of mindfulness based stress reduction (MBSR) on attention, rumination and resting blood pressure in women with cancer: a waitlist-controlled study. J Behav Med, 35, 262-271.

Yu, C., Xueling, Y., Liyuan, W., Xiaoyuan, Z. (2013). A randomized controlled trial of the effects of brief mindfulness meditation on anxiety symptoms and systolic blood pressure in Chinese nursing students. Nurse Education Today, 33, 1166-1172.

Zeidan, F., Johnson, S.K., Diamond, B.J., David, Z., Goolkasian, P. (2010). Mindfulness meditation improves cognition: Evidence of brief mental training. Consciousness and Cognition, 19, 597-605.

Zope, S.A., \& Zope, R.A. (2013). Sudarsh ankriya yoga: breathing for health. International Journal of Yoga, 6, 4-10.

How to cite this article: Arya N, Singh K, Malik A (2017), Impact of Five Days Spiritual Practice in Himalayan Ashram of Sahaj Marg on Well-Being Related Parameters and Selected Physiological Indicators, International Journal of Indian Psychology, Volume 4, Issue 2, No. 88, ISSN:2348-5396 (e), ISSN:2349-3429 (p), DIP:18.01.064/20170402, DOI: 10.25215/0402.064 